\title{
La Guía jurídica para la redacción de contratos internacionales de construcción de instalaciones industriales*
}

Fernando Vidal RamíreZ

La construcción de instalaciones industriales presenta problemas complejos de los más variados y diversos matices, que se pueden distinguir en técnicos y jurídicos. En relación a estos últimos, los contratos celebrados para el efecto generan un haz de relaciones jurídicas que van tomando características propias, máxime si se trata de contratos internacionales y, por ello, deben aplicarse las normas de conexión con los ordenamientos jurídicos extranjeros que contiene cada derecho nacional.

La guía responde al propósito de la Comisión de las Naciones Unidas para el Derecho Mercantil Internacional-CNUDMI, de servir de ayuda en la negociación y redacción de los contratos, sugiriendo soluciones a los problemas jurídicos y para lo cual ha tenido en consideración los ordenamientos jurídicos de los diversos países. No pretende la Guía tener un valor normativo, el cual sólo puede adquirirlo en la medida en que sus recomendaciones sean concordantes con el ordenamiento jurídico aplicable al contrato o que las partes convengan en adoptarlas en sus estipulaciones.

La guía comprende dos partes principales. La primera se refiere a las cuestiones previas a la redacción del contrato, tales como la definición del proyecto y de sus parámetros mediante los estudios preliminares, la selección de los sistemas de contratación y de selección del contratista para llegar a la celebración del contrato, sus formalidades y el cumplimiento de los requisitos para que inicie su vigencia. La segunda parte orienta la redacción del contrato, con el desarrollo de las estipulaciones que deben dar contenido a sus cláusulas.

Veamos, en primer lugar, la «internacionalidad» del contrato.

* Exposición del autor en el Seminario Internacional: Un Derecho Mercantil Uniforme para el Siglo XXI. 
La «internacionalidad» de un contrato es el resultado de varios criterios, para así calificarlo. Por un lado, el domicilio de las partes cuando se encuentran en países diferentes y, de otro, cuando se somete el contrato a leyes que no son, al menos, las del país del domicilio de una de las partes $\mathrm{y}$, aún, cuando se elige una ley que no corresponde al domicilio de ninguna de las dos partes.

La cuestión relativa a la ley aplicable al contrato es una de las primeras cuestiones a dilucidar, porque el contrato y las obligaciones que genera debe quedar sometido a un ordenamiento legal determinado, lo que conlleva a la elección por las partes de la ley aplicable, no estando demás indicar que, en nuestro Derecho, la ley que rija las obligaciones puede ser elegida por las partes siempre que la elección conste expresamente en el contrato conforme a la norma de conexión contenida en el Art. $2095^{\circ}$ del Código Civil peruano.

La Guía recomienda que la ley aplicable al contrato sea elegida por las partes y que esa ley sea la del país en el que se van a construir las instalaciones industriales. Sin embargo, advierte que en el país de la ley elegida puedan existir restricciones a la importación y una política cambiaria, arancelaria e impositiva que, junto con otras normas de orden público en relación a la protección del medio ambiente y a los requisitos de seguridad, puedan afectar determinados aspectos del contrato y también de la construcción. Por ello, la autonomía de la voluntad de las partes puede escindir determinados aspectos del contrato y someterlos a ordenamientos legales distintos, como puede ser que la ley del país del que vayan a provenir los equipos o materiales puede regir su suministro y la transmisión de su propiedad.

La ley aplicable genera también la cuestión relativa a la competencia jurisdiccional para la solución de las controversias que puedan suscitarse. A este respecto la Guía recomienda la negociación directa entre las partes, la conciliación y el arbitraje, procedimientos estos últimos y en relación a los cuales la CNUDMI ha contribuído grandemente con sus difundidos reglamentos que, por lo demás, han sido acogidos en nuestro país alentándose cada vez más estos medios de solución de controversias, siendo del caso expresar que en nuestra Constitución Política se reconoce la jurisdicción arbitral y que nada obsta para que las partes puedan convenir libremente su sometimiento a un arbitraje a desarrollarse en el país o en el extranjero. Sólo, porque -creo yo- no puede soslayarse, la Guía se remite a la solución de controversias mediante la intervención de la jurisdicción ordinaria.

La ventaja del arbitraje es evidente y no me corresponde abundar en el tema. Sólo quiero enfatizar que también el Estado puede someterse a 
arbitraje. En el Perú, el Estado y las personas jurídicas de derecho público pueden someter a arbitraje las controversias que se deriven de sus relaciones contractuales, conforme al Art. 63 de la Constitución Política, y la vigente Ley General de Arbitraje (Art. 92ㅇ) reglamenta el precepto constitucional haciéndolo extensivo al arbitraje internacional, dentro o fuera del país, aunque con la salvedad de que deba realizarse ante una institución arbitral de reconocido prestigio o ante arbitros designados mediante procedimientos contemplados en tratados que formen partedel derecho nacional.

Las cuestiones relativas a la ley aplicable y a la jurisdicción son importantes y las he tratado inicialmente porque ellas dan el marco dentro del cual se dan los sistemas de contratación y la selección del contratista, los procedimientos para celebrar el contrato, los requisitos para su validez y el modo como se van a ejecutar las correspondientes prestaciones, tanto en lo relativo a la ejecución de la obra como al pago de su valor.

Veamos, ahora, los sistemas de contratación y selección de contratistas.

Es obvio que la adopción del sistema de contratación corresponde a la parte que tiene el propósito de construir las instalaciones industriales, la que puede optar por celebrar un contrato con un solo contratista o con un grupo de contratistas, y, en esta segunda hipótesis celebrar varios contratos, uno con cada uno de los contratistas. Esta segunda hipótesis puede traer algunas dificultades no sólo para el propietario de la obra, que puede ver diluídas algunas responsabilidades, sino también para las mismas empresas contratistas, a las que se les puede presentar una falta de cohesión y de unidad de criterio en las ejecuciones de sus respectivas prestaciones y en la ejecución de la obra en su conjunto. Además, cabe la posibilidad de que normas imperativas del ordenamiento jurídico de país en el que se van a construir las instalaciones industriales dispongan la observancia de un determinado sistema de contratación.

La construcción de instalaciones industriales cuando son complejas y a gran escala puede estar fuera del alcance de una sola empresa contratista y determine que ésta se vea precisada a "consociarse» o a obtener el concurso de otras empresas a las que subcontrata.

La Guía no formula recomendación alguna respecto a los sistemas de contratación, pero los explica, con especial referencia a los denominados «sistema llave puesta en mano» y «sistema del contrato producto en mano".

En el "sistema de contrato llave en mano", que supone un único contrato, se encarga al contratista de todas las prestaciones necesarias para la terminación completa de las instalaciones, pudiendo incluir, ade- 
más, los estudios preliminares del proyecto y el financiamiento de la obra. En el "sistema del contrato producto en mano», el contratista, además de asumir las prestaciones inherentes al de la "llave en mano", compromete su garantía para el alcance de las metas de producción que han sido convenidas y para cuyo fin debe utilizar las materias primas y demás insumos que resultan indicados en el contrato.

Es obvio también que la selección del contratista corresponde también a la parte que tiene el propósito de construir las instalaciones industriales y para ello, conforme lo señala la Guía, hay dos métodos básicos, el de la licitación y el de la contratación directa.

Por el método de la licitación se convoca a las empresas a presentar ofertas y se llega a la selección del contratista con el cual se celebra el contrato en virtud de las calificaciones obtenidas y por estimarse su oferta como la más ventajosa. La licitación puede ser pública o privada, según se convoque a todas las empresas contratistas de obras y que estén interesadas en presentar ofertas, o, según se convoque sólo a algunas empresas, calificadas a priori por la parte que tiene el propósito de ejecutar la obra. Sin embargo, es posible, como lo advierte la Guía, que normas imperativas de la ley aplicable al método de selección del contratista, o bien las normas establecidas por la institución financiadora del proyecto, rigen el procedimiento para la contratación de la obra y que ellas conduzcan necesariamente a la licitación.

Si el método impuesto por las normas imperativas es el de la licitación, ésta debe ser organizada de la manera como lo establezcan tales normas con el margen que le permitan a la entidad licitante, pero, si se trata de obras públicas, la licitación es imperativa como imperativa es, en el Perú, la aplicación del Reglamento de Licitaciones y Contratos de Obras Públicas. El procedimiento de la licitación es formal y sus formalidades constituyen garantía tanto a la entidad licitante como a los postores.

Si la obra a ejecutarse es privada puede, sin limitaciones, seleccionarse al contratista por negociación y contratación directas. La Guía, para este caso, recomienda que la parte que tiene el propósito de ejecutar la obras entable tratativas con una o más empresas contratistas que estime en aptitud de construir las instalaciones industriales y les solicite ofertas, previo envío de la información y documentación que sean necesarias para posibilitar la formulación de las ofertas. Presentadas las ofertas, se procede a las tratativas definitivas que concluyan en la concertación del contrato.

En el método de la selección directa del contratista se arriba, en esencia, a un contrato privado que se concierta ejercitando las partes la 
autonomía de la voluntad, pues queda sometido a las normas de la codificación civil, salvo que el contrato se regule por leyes especiales. En el Perú, el Código Civil legisla sobre el contrato de obra, como una especie del género que viene a ser el contrato de prestación de servicios.

Si el contrato es el resultado de un procedimiento de licitación habrá de constar por escrito y, por lo general, se le lleva a ser contenido en una escritura pública. Si el contrato es consecuencia de la selección directa del contratista; la codificación civil, como en el caso de la peruana, no le prescribe forma al contrato, por lo que es sumamente atendible la recomendación de la Guía para que se le haga constar por escrito.

El contrato, como es lógico, ha de tener un plazo de vigencia, en relación al cual debe precisarse la fecha del inicio, que puede ser la fecha de celebración o al realizarse una condición suspensiva y, aún, del cumplimiento de un plazo suspensivo; que puede pactarse también como resolutorio. El plazo de vigencia del contrato tiene una relevancia tal que es necesario enfatizarlo y, por ello, la Guía aconseja la formulación de un calendario que establezca el orden en la ejecución de los trabajos con determinación de la fecha en que cada etapa deba quedar cumplida. Veamos, por último, aunque falta un buen trecho, el contenido del contrato.

El contenido del contrato plantea, como un primer tema a dilucidarse, el relativo a su interpretación. Por ello, la redacción del contrato requiere de una definición en cuanto al idioma en el que va a ser redactado. Lo ideal es que el contrato se redacte en un solo idioma, pero si las partes no hablan el mismo idioma, la Guía aconseja redactarlo en ambos idiomas con la estipulación del idioma que prevalecerá en caso de discrepancia y, si sobre las versiones del contrato en los idiomas diferentes las partes convienen en que tengan un mismo valor, entonces aconseja que se establezcan pautas para solucionar las controversias que de una diversa interpretación puedan suscitarse.

La interpretación del contenido del contrato es, pues, imprescindible facilitarla. Para tal fin, la Guía recomienda el uso de un vocabulario que permita definir conceptos o darles la mayor precisión posible, así como también que se especifiquen los antecedentes que pueden servir para la interpretación, pues ésta no está referida a lo que las partes quisieron sino a lo que expresaron, aunque con auxilio de los métodos de interpretación reconocidos en el Derecho.

Conjuntamente con la redacción del contrato es también conveniente que se precisen los documentos que se anexan como partes integrantes y, en relación a los cuales, el valor normativo o interpretativo que se les atribuye, su confidencialidad y a la parte a la que corresponde la pro- 
piedad sobre los mismos. Estos anexos deben comprender, pues, la descripción de las instalaciones que han de construirse, sus características, especificaciones, planos y, en general, todos los aspectos técnicos que contribuyan a establecer el objetivo perseguido por el dueño de la obra y al que se compromete el contratista asumiendo sus responsabilidades y en respaldo de las cuales pueda, si así se conviene en el contrato, constituir una fianza que la Guía presenta como «fianza de calidad».

Los servicios del contratista pueden suponer una transferencia de tecnología, que consiste en dar conocimiento al propietario de la obra de la información técnica, lo que supone también las correspondientes previsiones en el contrato. Esta transferencia de tecnología, según la Guía, puede tener lugar mediante la concesión de licencias de propiedad industrial, la iniciación de una operación conjunta entre ambas partes contratantes, la comunicación de conocimientos técnicos de carácter confidencial o la capacitación del personal del propietario de la obra.

La transferencia de tecnología puede dar lugar a que se pacten derechos o regalías a favor del contratista, el que deberá dejar establecido la no existencia de terceros con derecho a reclamar por la tecnología aplicada a la obra y, eventualmente, a constituir una fianza por el contratista y también por el propietario de la obra en garantía de la confidencialidad de la tecnología que le ha sido transferida. El precio y sus condiciones de pago son cláusulas relevantes en el contrato.

En primer lugar, debe establecerse el método para la determinación del precio. Según la Guía, pueden adoptarse los métodos del precio alzado, el de costos reembolsables y el del precio unitario. El precio alzado o de suma alzada consiste en la obligación del propietario de la obra de pagar un determinado importe que permanece constante, salvo que se reajuste o se modifique. El método de costos reembolsables consiste en la obligación del propietario de la obra de pagar todos los costos que razonablemente el contratista haya tenido que sufragar en la ejecución de la obra, además de la retribución convenida, asumiendo el propietario el riesgo de que el monto de los costos supere al previsto en la fecha de la celebración del contrato, aun cuando es lícito pactar limitaciones. El precio unitario consiste en que las partes convengan en un precio por unidad de construcción, resultando el precio total de las unidades, asumiendo también el propietario el riesgo del aumento del costo si la cantidad real de unidades supera la estimada al momento de la celebración del contrato, siendo de cargo del contratista el riesgo del aumento del costo de cada unidad.

Cualquiera que sea el método convenido, puede pactarse también que si el propietario está interesado en que la obra se termine antes del 
plazo estipulado pagará una prima, cuyo cálculo debe ser resultado del acuerdo de partes.

Frente al fenómeno inflacionario y devaluatorio que traen consigo fluctuaciones cambiarias, a veces muy severas, los contratantes pueden optar por una moneda que tenga estabilidad y que evite el riesgo cambiario, máxime si la política económica de nuestros días va erradicando los sistemas controlistas y alienta la libre convertibilidad y circulación de moneda extranjera. Esta previsión puede adoptarse con cualquiera de los métodos de determinación del precio.

Las condiciones de pago pueden ser libremente pactadas.

Hemos anteriormente calificado al contrato como complejo, pues de suyo lo es, máxime si también tiene que dar cabida a cláusulas relativas al suministro de equipos y materiales. Como se sabe, el suministro es un contrato distinto al de compraventa y, más aún, del contrato de obra, aunque pueden vincularse estrechamente, al extremo que puede quedar contenido en el mismo documento contractual y en virtud del cual se van a construir las instalaciones industriales.

El suministro debe dar lugar, pues, en sus cláusulas correspondientes a la descripción de los equipos y materiales que se van a suministrar, precisándose las obligaciones del contratista y la oportunidad y el lugar de la entrega y su transporte y a la parte a la que corresponde sufragar los gastos, encargarse del despacho aduanero y asumir el pago de los derechos arancelarios, y de su almacenamiento, si es del caso. La Guía aconseja, además, que en las cláusulas del contrato se prevea también el suministro de piezas de repuesto para después de concluída la construcción y la prestación de servicios técnicos, por el plazo que las partes acuerden, para el mantenimiento y la conservación de las instalaciones industriales.

Un aspecto vinculado al suministro y que considero que debe destacarse es el relativo al riesgo. Los equipos y materiales pueden perderse o sufrir daños, en las propias instalaciones, antes o después de su terminación, los que pueden producirse por causa imputable a las partes o por caso fortuito o fuerza mayor, todo lo cual debe preverse en el contrato. Este aspecto tiene sus complejidades y la Guía lo remite a lo estipulado en el contrato siempre que no se contravengan normas imperativas, o a lo que establezca la legislación aplicable, aconsejando que sea el contratista el que asuma el riesgo respecto de sus propios equipos y si se han incorporado a la obra, así como los materiales, estarse a lo pactado pues en mucho depende el método adoptado para la fijación del precio.

La Guía aconseja la contratación de un seguro, por el contratista no sólo que cubra el riesgo de pérdida o daños de los equipos y materiales 
sino también por los siniestros que puedan ocurrir durante la construcción y aun después de terminada hasta su entrega al propietario.

Cuestión vinculada al riesgo, y de ahí también la necesidad de contratar un seguro, es la relativa a la propiedad de los equipos y materiales empleados en la construcción de las instalaciones industriales, pues ella tiene importancia respecto al seguro y además a los impuestos y a una eventual responsabilidad ante terceros. Por ello, el contrato deberá contener cláusulas precisas en las que, al igual que en el caso del riesgo, habrá de tenerse en consideración el método adoptado para la determinación del precio.

La Guía aconseja que el propietario de la obra se haga asesorar por un consultor, que debe ser un ingeniero, quien en su nombre puede adoptar determinadas medidas de conformidad con el contrato. Es conveniente, como lo enfatiza la Guía, que en el contrato se precisen las facultades y funciones del consultor a fin de evitar interferencias con las del contratista, estableciendo hasta que punto sus actos pueden ser vinculantes para las partes. De ahí, que sea conveniente que en el contrato se establezca también el procedimiento para su contratación y para su eventual reemplazo.

El asesoramiento que requiere el propietario de la obra puede darse también en otras especialidades, como en el caso del seguro.

El contrato debe contemplar lo relativo a la subcontratación, que es la contratación de un tercero para que ejecute alguna de las obligaciones que el contrastista ha contraído en virtud del contrato, sea para permitirla o para prohibirla. Si el contrato permite la subcontratación, la Guía considera conveniente incluir en el contrato cláusulas relativas a la selección de los subcontratistas, ya sea que esté a cargo del contratista o de éste y del propietario de la obra, así como el alcance de los trabajos que se le va a encomendar. Este aspecto reviste especial importancia en cuanto a la responsabilidad imputable por los actos del subcontratista, pues las consecuencias de estos actos suponen también la responsabilidad del contratista que puede llegar a establecerse de manera solidaria, salvo que el propietario de la obra haya seleccionado al subcontratista y se haya reservado para sí la reclamación de los daños y perjuicios por la responsabilidad que le pueda ser imputable.

Así como puede contemplar la subcontratación puede también el contrato considerar la autorización, a cualquiera de las partes, para transmitir los derechos y obligaciones nacidas del contrato, total o parcialmente, estableciéndose las condiciones y los requisitos para hacerlo, aconsejando la Guía que también se indiquen las consecuencias de una cesión del contrato con infracción de las cláusulas que la norman. 
Durante la ejecución de las obras pueden verificarse inspecciones y pruebas tendientes a establecer que se viene realizando conforme al contrato. La Guía estima conveniente que este aspecto sea también previsto por las partes, describiéndose el carácter de las inspecciones y pruebas y su periodicidad, lo que debe constituir una prerrogativa del propietario de la obra. Frente al resultado insatisfactorio, es conveniente también que se prevea en el contrato la manera como el contratista deberá corregir los defectos que se detecten.

La verificación de inspecciones y pruebas reviste importancia también en lo que respecta a la terminación de la obra, pues de ser satisfactorias facilitarán su entrega y aceptación por el propietario. El contrato puede preveer una prueba final cuyo resultado se haga constar en un acta que suscriban el contratista y el propietario y que sea el punto de partida para la aceptación de la obra.

El contrato entre el propietario de la obra y el contratista es, incuestionablemente, de prestaciones recíprocas y esta característica habrá de determinar que cada una de las partes se requieran garantías que aseguren el cumplimiento de las que a cada una le corresponden. Estas garantías, por lo general, son de naturaleza personal.

Es usual que al contratista se le comience por requerir una fianza para que mantenga la oferta hasta la celebración del contrato y luego una fianza de buena ejecución de la obra, por lo general constituída por una empresa bancaria, la que incluso puede ser previamente calificada por el propietario de la obra, el mismo que precisa sus características y condiciones. Por su parte, puede también el contratista requerir que el propietario de la obra le otorgue una fianza, también constituída por una empresa bancaria, u otra garantía que podría ser de naturaleza real, para asegurar el pago del precio.

Si bien hemos indicado las garantías que recíprocamente pueden exigirse las partes para asegurar el cumplimiento de las prestaciones que vienen a ser las fundamentales, el contrato puede prever también garantías para los casos de atraso en el cronograma previsto para la ejecución de la obra o cualquier otro tipo de demora imputable al contratista, así como por cumplimiento tardío o defectuoso y, en general, para cualquier tipo de incumplimiento. De la misma manera en cuanto al cumplimiento de la prestación fundamental a cargo del propictario de la obra, que puede consistir en atraso en los pagos parciales que deba realizar u otro incumplimiento.

Las partes pueden convenir también en cláusulas penales, determinando con anticipación las indemnizaciones que corresponda pagar para cada caso de incumplimiento. Estas cláusulas por lo general se utilizan 
en previsión de posibles incumplimientos del contratista y sus ventajas son evidentes, pues le permiten al propietario de la obra obtener el pago indemnizatorio sin necesidad de probar los daños y perjuicios en un proceso judicial o arbitral, eliminando los gastos de tal proceso y la incertidumbre de su resultado. Pero también ofrecen ventajas al contratista, desde que con estas cláusulas limita su responsabilidad. Desde luego, habrá que estar a lo que la legislación aplicable regule sobre las cláusulas penales y en este sentido la Guía es sumamente cautelosa.

En efecto, la Guía no descarta la posibilidad de que además de las cláusulas penales puedan haber reclamaciones por daños y perjuicios y, en tal caso, la penalidad se computa como pago a cuenta de la indemnización, si ésta resultare ser una suma mayor.

Pero así como hay lugar a reclamaciones indemnizatorias, o a su limitación mediante las cláusulas penales, el contrato puede dar también contenido a cláusulas exoneratorias de responsabilidad. En este caso la Guía es también sumamente cautelosa y aconseja la mayor precisión posible en cuanto a las causas impedientes del incumplimiento exonerado, siempre con la salvedad de lo que puedan establecer las normas imperativas de la legislación aplicable.

La Guía hace también referencia a las que denomina cláusulas de gravosidad y que guardan similitud con lo que en nuestro sistema jurídico viene a ser la excesiva onerosidad en la prestación, que el Código Civil regula como una medida para mantener la conmutatividad de los contratos de prestaciones recíprocas. Estas cláusulas, según la Guía, tienen el destino de prever la renegociación del contrato, por lo que aconseja la mayor precisión posible en los hechos o acontecimientos extraordinarios que motiven su aplicación.

En el curso de la ejecución de la obra pueden presentarse situaciones que hagan aconsejable introducir modificaciones en la construcción. Por ello, la Guía aconseja también que se hagan previsiones en el contrato en cuanto a las circunstancias en las que el contratista, a solicitud del propietario de la obra, resultase obligado a introducirlas pero siempre que se hagan conforme a los criterios enunciados en el contrato o que el contratista se oponga, para cuyo efecto el contrato tiene que haber previsto la razonabilidad de los motivos o, aviniéndose el contratista a las modificaciones, deje constancia escrita. Como las modificaciones pueden crear controversias entre el contratista y el propictario, la Guía aconseja también que se haga previsión en el contrato sobre la manera de solucionarlas.

En el curso de la ejecución de la obra pueden también presentarse situaciones que hagan aconsejable la suspensión de la construcción. La 
Guía ha reparado también en esta posibilidad y aconseja también que se haga la debida previsión en el contrato, sea que la suspensión se haga a instancia del propietario o a instancia del contratista, previéndose también el procedimiento que debe preverse en el contrato para que las partes hagan uso de esta facultad. La suspensión puede originarse por múltiples causas, que es necesario armonizar con las demás cláusulas del contrato, en el que también debe preverse las consecuencias de la suspensión y la reanudación de la ejecución de la obra.

La Guía aconseja que el contrato de contenido a cláusulas resolutorias, en las que no sólo se estipulen las causales sino que además se establezca el procedimiento para la resolución del contrato. Tal vez, desde la perspectiva de nuestro sistema jurídico convenga hacer una precisión, por cuanto la Guía parece ser que usa indistintamente la resolución y la rescisión, cuando nuestro Código Civil las distingue claramente y ha definido su diferenciación. La rescisión, según nuestro Código Civil, deja sin efecto un contrato por causal existente al momento de celebrarlo (Art. 1370) mientras que la resolución lo deja sin efecto por causal sobreviniente (Art. 1371). La acotación es importante, por cuanto el uso indistinto de la resolución y de la rescisión no sólo podría generar confusión sino también problemas, el efecto de la rescisión se retrotrae al momento de la celebración del contrato y el de la resolución al momento de la causal que la motiva, obligando la resolución a las partes a restituirse las prestaciones en el estado en que se encontraran al momento indicado y, si no fuera posible, a reembolsarse en dinero su valor (Art. 1372), lo que no puede ocurrir con la rescisión pues para su aplicación nuestra ley le fija un plazo relativamente breve y como plazo de caducidad.

Visto el contenido del contrato nos resta considerar los aspectos relativos a la terminación de la obra, su entrega y aceptación por el propietario.

La Guía aconseja que en el contrato se especifique claramente cuando se entenderá concluída la obra mediante las pruebas necesarias y que hayan sido especificadas en el contrato, así como el plazo para practicarlas y la parte que debe asumir el costo. Para tal efecto, no sólo puede convenirse en el plazo para las pruebas sino también el procedimiento para practicarlas. Si las pruebas resultan insatisfactorias, el contratista queda obligado a repetirlas.

Si las pruebas de terminación son satisfactorias se debe dar lugar a un informe del contratista al propietario.

La entrega de la obra por el contratista y su aceptación por el propietario depende del sistema de contratación y si se ha establecido un 
período de funcionamiento a prueba, todo lo cual debe estar previsto en el contrato.

El propietario está obligado a aceptar las instalaciones luego de practicadas las pruebas de funcionamiento, para cuyo efecto la Guía aconseja el otorgamiento de un acta que debe ser suscrita por el contratista y el propietario, aconsejando también que el contrato determine las consecuencias jurídicas de la aceptación de la obra.

Como puede apreciase, pues, la Guía constituye una contribución de suma importancia en la negociación y redacción de contratos internacionales para la construcción de instalaciones industriales y lo hace con suma prolijidad y cuidando de montar el escenario completo en que deben desarrollarse las negociaciones y plasmarse las precisiones y previsiones de un contrato tan complejo del que emerge un haz de situaciones y relaciones jurídicas.

Para terminar, me voy a tomar la licencia de exponer unas vivencia personal. Al hacer el resumen que dejo expuesto, me ha venido a la memoria que hace más de 20 años participé como asesor de la Empresa Minera del Perú en las negociaciones, primero, y en la redacción, después, del contrato que celebró con el Consorcio Japonés MitsuiFurukawa para la construcción de la refinería de cobre en el puerto de Ilo, bajo la modalidad de "llave puesta en mano". Pienso, ahora, recordando las intensas tratativas que se desarrollaron y las enormes dificultades, no sólo para poner de acuerdo a las partes, sino en la redacción misma del contrato, en el que era necesario prever toda la gama de situaciones que podían presentarse, lo aliviado que hubiera sido el trabajo de los abogados y técnicos que entonces participamos de haber contado con la Guía que he resumido en esta exposición y cuya utilidad es incuestionable y su utilización indispensable. 